\title{
NOTA \\ TEORÍA SEMÁNTICA Y TRADUCCIÓN
}

\author{
José Luis Cifuentes Honrubia \\ (Universidad de Alicante)
}

G. Mounin (1976) señaló que los problemas de la traducción implican, explícitamente o no, la posesión de una psicología del lenguaje y de una lingüística general, en definitiva, una teoría del lenguaje. El mismo Mounin (1971) resume adecuadamente las dificultades de traducir en dos puntos: causas de orden cultural, en tanto que se trata de pasar ciertas realidades no lingüísticas de una cultura a otra, y causas propiamente lingüísticas, en tanto que los contenidos referidos están formalizados de distinta manera en una lengua u otra.

Jakobson (1975) deja abierta la traducción al entender que toda experiencia cognitiva - y el lenguaje lo es - puede ser expresada en cualquier lengua; sin embargo, el mismo autor señala que si las lenguas difieren unas de otras no es tanto por lo que pueden expresar, sino por lo que deben expresar. Y es en este sentido en el que debemos señalar que lo esencial de una actividad traductora no es tanto el encontrar las equivalencias de una lengua a otra, sino el practicar una exégesis del texto a traducir, pues la traducción no opera sobre las lenguas, sino sobre los mensajes (Lederer, 1973). Evidentemente esta teoría interpretativa de la traducción considera funcionalmente pertinente la importancia de la situación y del contexto para establecer el sentido completo. La palabra no es una unidad con contornos definidos, sino una encrucijada de influencias, no tiene un sentido fijo, para siempre, y que simplemente se suma a los de las otras palabras contiguas. Por contra, la palabra tiende a comúnar su sentido con el de otra $\mathbf{u}$ otras hasta constituir uno total del sintagma, que a su vez experimenta el mismo proceso dentro de las unidades superiores.

Se podrá objetar que el lenguaje no es sólo contenido, sino simbolización, y en algunas ocasiones la expresión puede jugar un papel fundamental, como en la 
literatura. Pero entropía, pérdida de información, hay en todo proceso comunicativo, incluso intralingual, y más si es literario.

A una consideración sobre una teoría semántica textual y cognitiva, como la planteada anteriormente, se ha llegado no sólo desde la teoría de la traducción, sino también desde la propia lingüística. Así, Wunderlich (1982) ha llegado a concluir que la traducción de preposiciones no supone adecuación o inadecuación de traducciones, sino «simplemente» que los objetos pueden ser categorizados de distinta forma en cada lengua. Piénsese en un ejemplo como el siguiente: En la calle / al carrer / dans la rue / in the street / auf der Straße.

Estas traducciones, por ejemplo, no implican que auf o in no puedan ser traducidas adecuadamente por sur, dans u otras preposiciones, sino que «la calle» es categorizada en alemán de manera distinta al francés o español. Al igual que, por ejemplo, los esquemas (Cifuentes, 1994) que configuran los verbos de movimiento ir, venir, traer, llevar, son muy distintos en español y el resto de lenguas europeas: en ejemplos como «I will come there tomorrow» 0 «I came over to your house last night, but you weren't home» (si el hablante no está en la casa en el momento de la enunciación) la traducción al español no puede hacerse con los esquemas semánticos del verbo «venir». Los diferentes esquemas de uso son debidos a diferentes conceptualizaciones de la misma situación real. A través de la interpretación del simple contenido proposicional de una expresión, que resulta de una representación interlingual del significado, tenemos que interpretar cómo el conceptualizador escoge construir la situación para expresarla según ello (Zelinsky-Wibbelt, 1993: 352-353).

Una teoría semántica que trate de dar cuenta de unos procesos semánticos como los anteriores tiene que ser cognitiva a la fuerza, de ahí la obligada consideración de la llamada «Lingüística Cognitiva» (Langacker, 1987, 1991: Lakoff, 1987, principalmente), aunque «corregida» con las principales aportaciones del estructuralismo europeo al respecto, como son las nociones de significante complejo, el significado en su configuración paradigmática y combinatoria, las nociones de variante e invariante de contenido, etc. (Rastier, 1991; Cifuentes, 1994).

La Lingüística Cognitiva es una teoría basada en el uso, siendo el lenguaje parte integral de la cognición humana, no existiendo los objetos de la realidad independientemente de los esquemas conceptuales, al depender las conceptualizaciones de nuestra biología y la cultura. Para ser objetivos, pues, debemos estar enterados de que tenemos un particular sistema conceptual, debemos conocer cómo es, y debemos ser capaces de abrigar alternativas: el reconocimiento de esquemas conceptuales alternativos no abandona la objetividad, simplemente la hace posible.

La estructura semántica es estructura conceptual convencionalizada, y la gramática es la simbolización convencional de la estructura semántica. La 
esencia de la propuesta de una Semántica Cognitiva, es que las significaciones son relativas a las escenas, pero no unas escenas tal y como son «realmente», sino tal y como son conceptualizadas. Una escena del mundo real es percibida concordando con el grado en que armoniza determinadas estructuras prototípicas conceptuales con la escena exterior. Lo que quiero decir es que operamos con modelos cognitivos idealizados (M.C.I.), que articulan y organizan distintos esquemas mentales, y estos modelos son organizaciones de la sustancia del contenido. Al conformar semióticamente esa sustancia del contenido, es decir, al expresarla lingüísticamente mediante determinada forma, no sólo nos vemos constreñidos por la estructura inmanente de la lengua en cuestión, sino por la propia situación.

Esta perspectiva sobre la significación supone una necesaria interdependencia entre semántica y pragmática, al asumir que las categorías lingüísticas presuponen particulares conocimientos estructurados de instituciones culturales, creencias acerca del mundo, experiencias mostradas, formas comunes o familiares de ver o hacer las cosas, etc., siendo el límite entre conocimiento lingüístico y enciclopédico la relación complementaria que los une.

En Gramática Cognitiva, las estructuras semánticas son caracterizadas como estructuras conceptuales que han sido convencionalizadas para los propósitos de la simbolización lingüística. Dada la naturaleza convencional de la estructura semántica, se sigue que mientras las estructuras conceptuales pueden o no ser universales, las estructuras semánticas no lo son. La convencionalización está en función de una comunidad. Incluso si dos comunidades diferentes convencionalizan el mismo contenido conceptual básico, puede haber diferencias significativas en la manera en que es conceptualizado. Así pues, en Lingüística Cognitiva, la significación está basada en la comprensión, y la existencia de modos contradictorios de comprender una situación no es un problema. La finalidad de la Semántica es descubrir la naturaleza de la relación entre textos lingüísticos y la comprensión por parte del enunciatario de los textos en sus contextos. Los M.C.I. representan organizaciones particulares de conocimiento que se establecen como un prerrequisito para nuestra capacidad de comprender las significaciones.

La significación de una expresión no es determinada de forma única o mecánica desde la naturaleza de la situación objetiva que describe. La mismá situación puede ser descrita por una variedad de expresiones distintas senánticamente que articulan diferentes maneras de construirla o estructuraria. Nuestra capacidad para imponer estructuraciones alternativas a un fenómeno concebido es fundamental para la variabilidad léxica y gramatical (Langacker, 1987: 107).

Las expresiones lingüísticas pertenecen a situaciones conceptualizadas o escenas. Sin embargo, la significación de una expresión no es adecuadamente 
caracterizada al identificar o describir la situación en cuestión. Por un lado, las expresiones difieren en la significación dependiendo de lo que las entidades dentro de la situación designan. Pero la designación es sólo una caso especial de la capacidad de los hablantes para construir la misma situación básica de diferentes maneras, es decir, para estructurarla por medio de imágenes alternativas. Las imágenes que contrastan impuestas sobre una escena dan cuenta de las experiencias mentales cualitativamente diferentes. Consecuentemente, la imagen articulada por una expresión lingüística - la manera convencionalmente establecida en que estructura una situación-constituye una faceta crucial de su significación.

Cualquier expresión lingüística, en su plano semántico, estructura una situación conceptualizada (o escena) por medio de una particular imagen. Al conceptualizar una escena con propósitos expresivos, el hablante (y secundariamente el oyente, al reconstruir la intención del hablante) está obligado a elegir respecto de los varios parámetros de ajustes focales. El hablante (u oyente) al escoger las construcciones focales apropiadas y estructurar una escena de manera apropiada, establece una relación constructiva entre él mismo y la escena estructurada. Los parámetros que podemos señalar como ajustes focales y que intervienen en la estructuración de las escenas son tres: la selección, que determina qué facetas de una escena están siendo tratadas; la perspectiva, que muestra la perspectiva desde la que una escena es vista; la abstracción, que pertenece al nivel de especificidad en que una situación es dibujada.

La estructura gramatical está basada en las imágenes convencionales, que reflejan nuestra capacidad para construir una situación conceptualizada de maneras alternativas. El valor semántico o conceptual total de una escena es función no sólo de su contenido, sino también de cómo estructuramos este contenido con respecto a la atención, seleción, organización figura/fondo, punto de vista y nivel de esquematicidad. A la vista de esto somos capaces de hacer ajustes, y por ello transformar una conceptualización en otra que es altamente equivalente en términos de contenido, pero difieren en cómo este contenido es construido.

El plano semántico, pues, es la significación contextual de una expresión, es decir, la conceptualización detallada que constituye nuestra comprensión total de la expresión en contexto, e incluye todos los aspectos relevantes de la situación, es decir, esta significación contextual es enciclopédica. Pero no pretendemos que todas las facetas de nuestro conocimiento de una entidad tengan igual estatuto, sino todo lo contrario. La multitud de especificaciones que figuran en nuestra concepción enciclopédica de una entidad forman una gradación en términos de su centralidad. Hay algunos caracteres centrales que no pueden ser omitidos, mientras que otros son periféricos. La centralidad se correlaciona con los rasgos de convencional, genérico, intrínseco y característico. 
Así pues, organizamos nuestro conocimiento por medio de estructuras llamadas M.C.I., y las estructuras de categorías y los efectos prototípicos (Cifuentes, 1994: cap. IV) son elementos de esa organización. Un M.C.I. es equivalente a los marcos de Fillmore o Minsky, espacios mentales de Fauconnier, esquemas de Talmy o Rumelhart, escenarios de Schank y Abelson, y dominios cognitivos de Langacker. Podemos entenderlo como un tipo de conocimiento base o complejo conceptual estructurado relativo al cual una noción es caracterizada. Lakoff (1987) identificará cuatro tipos de M.C.I. según los principios estructurales que manejen: 1. Proposicionales: especifican elementos, sus propiedades y las relaciones que los unen. 2. Esquemas de imágenes: especifican la esquematización de determinadas imágenes, como trayectorias, longitudes o formas. 3. Metafóricos, en los que un dominio es comprendido en términos de otro. 4. Metonímicos, donde un submodelo es usado para comprender la categoría como conjunto.

Un modelo teórico como el anterior implica que la traducción de cualquier elemento lingüístico suponga la necesidad de explicitación de sus condiciones de empleo por medio de esquemas cognitivos para cada lengua. Evidentemente estas reglas no son para aprenderlas, sino para que podamos emplearlas en la distinción de las expresiones cuyo uso tenemos que aprender y de las situaciones de aprendizaje. Lo esencial de una actividad traductora consistirá en practicar una exégesis o interpretación del texto elegido; es decir, no se trataría de estudiar cómo se dice determinado elemento en cierta construcción por distintas lenguas, sino qué esquemas cognitivos se aplican a una misma escena en diferentes lenguas (Lewandowska-Tomaszczyk, 1992). Al estar conceptualmente mediada, la realidad no está expresada directamente por una lengua. Más bien, una lengua expresa cómo los hablantes tienen mental e históricamente asumida la experiencia común del entorno físico en que viven.

\section{Referencias bibliográficas:}

CIFUENTES HONRUBIA, J. L. (1994): Gramática cognitiva. Fundamentos críticos, Eudema, Madrid.

JAKOBSON, R. (1975): «Aspectos lingüísticos de la traducción», Ensayos de Lingüística General, Seix Barral, Barcelona.

LAKOFF, G. (1987): Women, fire and dangerous things, University of Chicago Press, Chicago.

LANGACKER, R. W. (1987): Foundations of Cognitive Grammar, I, Stanford University Press, Stanford.

LANGACKER, R. W. (1991): Foundations of Cognitive Grammar, II, Stanford University Press, Stanford. 
LEDERER, M. (1973): «La traduction: transcoder ou réexprimer?», Études de Linguistique Appliquée, 12, págs. 7-25.

LEWANDOWSKA-TOMASZCZYK, B. (1992): «Cognitive linguistics, translation and lexioography», in Actas del IX Congreso Nacional de AESLA, AESLA, Bilbao, págs. 49-65.

MOUNIN, G. (1971): Los problemas teóricos de la traducción, Gredos, Madrid. MOUNIN, G. (1976): Linguistique et traduction, Dessart et Mardaga, Bruxelles. RASTIER, F. (1991): Sémantique et recherches cognitives, Puf, Paris.

WUNDERLICH, D. (1982): «Langage et espace». DRLAV, 27, págs. 63-82. ZELINSKÝ-WIBBELT, C. (1993): «Interpreting and translatin prepositions: A congnitively based formalization», in C. Zelinsky-Wibbelt (ed.): The Semantics of Prepositions, Mouton de Gruyter, Berlin-New York, págs. 351-390. 